\title{
STUDY OF INSULIN RESISTANCE AND THYROID PROFILE IN WOMEN WITH SPONTANEOUS ABORTIONS
}

\author{
Gynaecology
}

\section{Annapoorani R}

Assistant Professor, Department of Obstetrics and gynecology, Government Rajaji Hospital, Madurai Medical College.

Nagasutha D*

Assistant Professor, Department of Obstetrics and Gynecology, Government Rajaji Hospital, Madurai Medical College, Madurai, Tamilnadu. * Corresponding Author

\section{ABSTRACT}

Thyroid dysfunction and insulin resistance are important endocrinological causes of spontaneous abortions. This study is aimed at finding alterations in thyroid profile, glucose and insulin levels in women with spontaneous abortions. The present study is a case control study where 75 patients with spontaneous abortions below 20 weeks were taken as cases and 75 patients with normal on going pregnancy without previous history of miscarriage were taken as controls. Thyroid Function Tests (Free T3 ,Free T4,TSH), Oral Glucose Tolerance Test following 75 mg glucose load were done in cases and controls. Fasting glucose and insulin levels were measured and Insulin resistance was calculated using homeostatic model assessment method (HOMA- IR).Free T3 levels were significantly lower and TSH levels were significantly higher in study group indicating the presence of hypothyroidism in the abortus group. The HOMA-IR insulin resistance scores were apparently higher in the study group than in the controls, but it was not statistically significant.

\section{KEYWORDS}

spontaneous abortions, thyroid profile, insulin resistance, homeostatic model assessment

\section{INTRODUCTION}

Approximately $15 \%$ of clinically recognized pregnancies result in spontaneous losses1. Spontaneous abortion is defined as an involuntary termination of pregnancy before 20 weeks of gestation or a fetal weight of less than 500 grams. A successful pregnancy requires a precise integration of genetic, hormonal, immunological and cellular events. Spontaneous pregnancy losses can be physically and emotionally taxing to the couples, especially when faced with recurrent losses. Recurrent pregnancy loss (RPL) is defined as three consecutive spontaneous abortions. The incidence of RPL is approximately 1 in 300 pregnancies 2 . The accepted etiologies for RPL include chromosomal abnormalities, uncontrolled hypothyroidism, uncontrolled diabetes mellitus, certain anatomical uterine anomalies and anti phospholipid antibody syndrome. Other probable and possible etiologies include additional endocrine disorders, inherited or acquired thrombophilias,immunological abnormalities and environmental factors.

Thyroid disorders are commonest endocrine disorders in women of child bearing age and therefore encountered commonly in pregnancy. Polycystic Ovarian Syndrome(PCOS) is associated with early spontaneous abortions as evidenced in many studies with an incidence of $21-56 \% 3$. The exact role and mechanism of pregnancy loss in PCOS remains uncertain though $40 \%$ of women with PCOS have insulin resistance as a predominant feature. Some studies have proved that insulin resistance plays a significant role in spontaneous losses. It is well known that epidemiology of endocrinological problems vary from place to place. The present study was carried out to determine if thyroid dysfunction and insulin resistance play a causative role in spontaneous pregnancy loss. The study also aims at bringing out any correlation between the two factors in our patient population.

\section{MATERIALS AND METHODS}

This was a case - control study undertaken in the Department of Obstetrics and Gynecology, Madurai Medical College, Madurai during the period between August 2018 to August 2019.

Seventy five patients with spontaneous abortions less than 20 weeks gestation irrespective of their previous pregnancy outcome were taken as cases. Seventy five women with normal ongoing pregnancy of corresponding gestational age without previous history of miscarriage were taken as controls.

\section{Exclusion criteria-}

Women with the following conditions were excluded from the study

- Multiple pregnancy

- Uterine anomalies

- Medical disorders like
1. Anemia

2. Diabetes mellitus

3. Hypertension

4. Hypothyroidism

- Uro-genital infections

Parameters Analyzed-

- Oral Glucose Tolerance Test(OGTT)

- Fasting Insulin

- Insulin Resistance

- Thyroid Profile

- FreeT3

- FreeT4

- TSH

\section{PROCEDURE}

After a patient was recruited to the study, written informed consent was taken. A detailed history was taken with importance to past obstetric history. Then a thorough physical examination was carried out which included general examination like presence of pallor and thyromegaly and pelvic examination to determine the clinical type of abortion.

After overnight fasting, $8 \mathrm{ml}$ venous sample was taken for thyroid profile, fasting plasma glucose,fasting plasma insulin. Thyroid function tests (Free T3, Free T4,TSH) were done in case and controls. Fasting insulin and fasting glucose levels were measured and Insulin Resistance was calculated using Homeostatic Model Assessment method (HOMA-IR). Oral glucose tolerance test following a $75 \mathrm{mg}$ glucose load was done in both cases and controls. $2 \mathrm{ml}$ venous blood sample was taken after 2 hours to determine 2 hour plasma glucose. Patients with fasting glucose $>126 \mathrm{mg} / \mathrm{dl}$ and 2 hour glucose $>200$ $\mathrm{mg} / \mathrm{dl}$ were considered to be diabetic. Patients with fasting glucose of $>110 \mathrm{mg} / \mathrm{dl}$ and $<126 \mathrm{mg} / \mathrm{dl}$ were considered to have impaired fasting glucose (IFG) . Patients with glucose of $>140$ and $<200 \mathrm{mg} / \mathrm{dl}$ obtained $2 \mathrm{hrs}$ after ingesting $75 \mathrm{mg}$ glucose load were considered to have impaired glucose tolerance (IGT). Laboratory investigations were done in the Department of Biochemistry, Madurai Medical College.

\section{Assessment of Insulin Resistance}

Fasting insulin levels were done by Radioimmunometric Assay, values were determined from standard graph and expressed as $\mu \mathrm{IU} / \mathrm{ml}$. Fasting insulin levels below $20 \mu \mathrm{IU} / \mathrm{ml}$ was taken as normal.

HOMA-IR $=$ Fasting plasma glucose $\times$ Fasting plasma insulin $/ 405$

HOMA -IR value of $>4.5$ was considered to be diagnostic of insulin resistance 4

Estimation of Free T3and Free T4 is done by Radio-Immuno Assay (RIA). 


\section{Normal Range}

- $\quad$ Free T3 -2.5 to $5.8 \mathrm{pM} / \mathrm{L}$

- Free T4 -11.5 to $23 \mathrm{pM} / \mathrm{L}$

- $\mathrm{TSH}-0.1$ to $4.05 \mu \mathrm{IU} / \mathrm{ml}$

Statistical Analysis is done using Student's t test.

\section{RESULTS}

In this study seventy five women with spontaneous abortions were taken as cases and compared with normal ongoing pregnancy. Among the cases, $52 \%$ were between the age of 20-25 years which matched with the controls. No significant difference was found between the abortus group and the control group in the parameters such as age,parity, gestational age and hemoglobin.

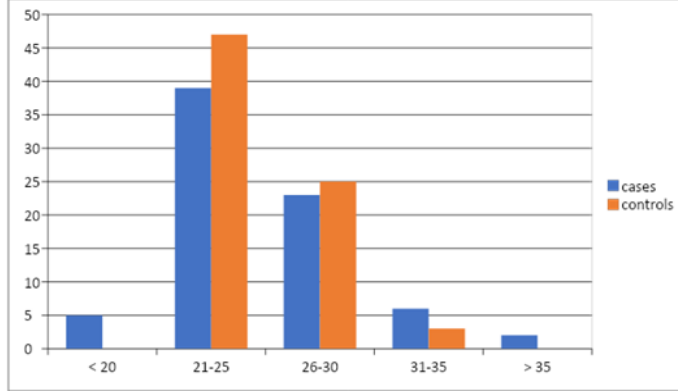

Fig. 1. Age distribution of cases and controls

Among the cases, nine had previous one abortion and eight had recurrent miscarriages (two-five). Of these 15 cases were missed abortions, one was complete abortion and one was inevitable abortion. Women with first abortion were 58, of which 35 were primigravidas and rest were multigravidas.

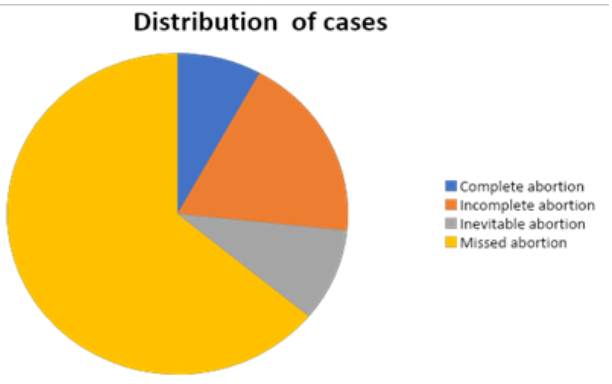

Fig. 2. Clinical types of abortions

Table 1: Thyroid profile comparision in both groups

\begin{tabular}{|c|c|c|c|c|c|}
\hline & \multicolumn{2}{|c|}{ Cases $(\mathrm{N}=75)$} & \multicolumn{2}{c|}{ Controls $(\mathrm{N}=75)$} & \multirow{2}{*}{$\begin{array}{c}\text { P } \\
\text { Value }\end{array}$} \\
\cline { 2 - 5 } & MEAN & SD & MEAN & SD & \\
\hline Free T3 $(\mathrm{pM} / \mathrm{L})$ & 3.283 & 0.762 & 3.719 & 1.092 & $0.005(\mathrm{~S})$ \\
\hline Free T4 $(\mathrm{pM} / \mathrm{L})$ & 14.856 & 3.241 & 15.581 & 2.904 & $0.151(\mathrm{NS})$ \\
\hline TSH $(\mu \mathrm{U} / \mathrm{ml})$ & 3.074 & 3.281 & 2.137 & 1.147 & $0.02(\mathrm{~S})$ \\
\hline
\end{tabular}

FT3 and FT4 levels were lower in the abortus group, but FT3 levels were significantly lower than the control group. TSH was found to be significantly higher in the abortus group when compared to controls.

Table 2. Interpretation of Thyroid profile

\begin{tabular}{|c|c|c|c|c|}
\hline \multirow{2}{*}{} & \multicolumn{2}{|c|}{ CASES $(\mathrm{n}=75)$} & \multicolumn{2}{c|}{ CONTROLS $(\mathrm{n}=75)$} \\
\cline { 2 - 5 } & No. & $\%$ & No. & $\%$ \\
\hline Subclinical Hypothyroid & 13 & 17.3 & 2 & 2.66 \\
\hline Overt Hypothyroid & 1 & 1.3 & 0 & 0 \\
\hline Subclinical Hyperthyroid & 0 & 0 & 0 & 0 \\
\hline Overt Hyperthyroid & 1 & 1.3 & 0 & 0 \\
\hline
\end{tabular}

\section{Table 3. GTT in both groups}

\begin{tabular}{|c|c|c|c|c|c|}
\hline & \multicolumn{2}{|c|}{ Cases $(\mathrm{N}=75)$} & \multicolumn{2}{c|}{ Controls $(\mathrm{N}=75)$} & \multirow{2}{*}{$\begin{array}{c}\text { P } \\
\text { Value }\end{array}$} \\
\cline { 2 - 5 } & MEAN & SD & MEAN & SD & \\
\hline FBS (mg/dl) & 75.23 & 14.44 & 72.85 & 9.013 & $0.229(\mathrm{NS})$ \\
\hline $2 \mathrm{hr} \mathrm{BS}(\mathrm{mg} / \mathrm{dl})$ & 112.01 & 20.516 & 99.29 & 18.497 & $0.11(\mathrm{NS})$ \\
\hline
\end{tabular}

The mean fasting glucose and $2 \mathrm{hr}$ glucose were higher among the cases than the controls, though it was not statistically significant.
Table 4. Serum Fasting Insulin levels and HOMA-IR

\begin{tabular}{|c|c|c|c|c|c|}
\hline & \multicolumn{2}{|c|}{ Cases (N=75) } & \multicolumn{2}{|c|}{ Controls (N=75) } & \multirow{2}{*}{ P Value } \\
\cline { 2 - 5 } & MEAN & SD & MEAN & SD & \\
\hline $\begin{array}{c}\text { Fasting Insulin } \\
(\mathrm{uU} / \mathrm{ml})\end{array}$ & 6.871 & 10.104 & 4.984 & 3.633 & $0.131(\mathrm{NS})$ \\
\hline HOMA-IR & 1.288 & 1.809 & 0.922 & 0.7 & $0.104(\mathrm{NS})$ \\
\hline
\end{tabular}

Table 5. HOMA-Insulin Resistance

\begin{tabular}{|c|c|c|c|}
\hline HOMA-IR & $\begin{array}{c}\text { CASES } \\
(\mathrm{N}=75)\end{array}$ & $\begin{array}{c}\text { CONTROLS } \\
(\mathrm{N}=75)\end{array}$ & P VALUE \\
\hline$>4.5$ & 6 & 0 & $0.112(\mathrm{NS})$ \\
\hline$<4.5$ & 69 & 75 & $0.435(\mathrm{NS})$ \\
\hline
\end{tabular}

Although fasting insulin levels and insulin resistance was higher among the abortus group, it was not statistically significant. Six women among the cases had HOMA-IR values $>4.5$, suggestive of insulin resistance.

Table 6. comparing IR and TFT

\begin{tabular}{|c|c|}
\hline & Number of cases \\
\hline IR only & 6 \\
\hline TFT abnormality only & 15 \\
\hline Both IR and TFT abnormality & 2 \\
\hline
\end{tabular}

Table 7. Outcome in Recurrent abortions

\begin{tabular}{|c|c|c|c|c|}
\hline & $\begin{array}{c}\text { IFG } \\
\% \\
\text { (No.) }\end{array}$ & $\begin{array}{c}\text { IGT } \\
\% \\
\text { (No.) }\end{array}$ & \begin{tabular}{|c|} 
HYPOTHY \\
ROID \\
$\%$ \\
(No.)
\end{tabular} & $\begin{array}{c}\text { IR } \\
\% \\
\text { (No.) }\end{array}$ \\
\hline $\begin{array}{c}\text { Recurrent } \\
\text { Abortions } \\
(n=17)\end{array}$ & $\begin{array}{l}11.7 \\
(2)\end{array}$ & $11.7 \quad(2)$ & $11.7 \quad(2)$ & $17.6 \quad$ (3) \\
\hline
\end{tabular}

\section{DISCUSSION}

Spontaneous pregnancy loss is the most common complication in early pregnancy. In our study $50 \%$ of cases and controls were in the age group of 20 to 25 years. Mean age among cases was $25.37+4.6$ and among controls $24.63+3.3$. There was no statistical significance in age between the two groups.

In our study the mean free T3 values were $3.283+0.76$ in the abortus group and $3.719+1.09$ in the control group which was significantly lower ( $\mathrm{p}-0.005)$. Free T4 were lower in the abortus group though it was not statistically significant. When TSH values were compared, the mean values were $3.074+3.28$ and $2.137+1.14$ in the abortus and control groups respectively and it was statistically significant. Donmez et al (2005) in their study on thyroid functions in spontaneous abortions had similar results 5 . Lower Free T3, Free T4 levels and higher TSH levels were obtained in the spontaneous abortion group suggesting a hypothyroidic situation in this group. It may lead to slowing down in the necessary synthesis and oxidation process, resulting in termination of pregnancy. Thus, there are several studies indicating the ratio of spontaneous abortions rise two fold in women with hypothyroidism. Matsua et al 6 showed that Free T3 and Free T 4 levels of women whose pregnancy terminated in abortion was significantly lower than those with healthy pregnancies that continued, which is parallel to our study.

A study by Pratt et al 7 found that the incidence of anti-thyroid antibodies in womn who had recurrent abortions were significantly higher than other non- organ specific auto-antibodies. Glinoer et al 8 in their prospective study also found that $8.3 \%$ of women with thyroid antibodies had spontaneous abortions when compared to $3.3 \%$ in the control group. However, in our study we evaluated only the thyroid function tests, as recent prospective studies emphasize that thyroid auto-antibodies are not responsible for spontaneous abortions.

In the results of $75 \mathrm{gm}$ GTT, two women in the abortus group had impaired fasting glucose, the result of which was statistically significant ( $\mathrm{P}$ value - 0.04). The mean fasting glucose values were higher than those in the control group, $75.23+14.44$ in cases vs $72.85+$ $9.01 \mathrm{i}$ the controls. The mean 2 hour blood glucose levels in cases was $112.01+20.51$ which was higher than in the control group $99.29+$ 18.49 , although the results were not statistically significant. 
In our study, insulin resistance was calculated using the HOMA-IR method. the mean fasting glucose and fasting insulin values were higher in the study group than in the controls, though it was not significantly higher. The mean fasting insulin level in the study group was lower than the level diagnostic of IR: $>20 \mathrm{uU} / \mathrm{Ml}$. The HOMA-IR scores for the study and control group were $1.288+1.8$ and $0.922+0.7$ respectively. The HOMA-IR score of $>4.5$ identified insulin resistance in 6 patients among cases $(8 \%)$ and none among controls. In our Study results were similar to the results of Diejomoah et al 9 . In their study 35 non-pregnant women with RPL were compared with 30 non-pregnant parous women without RPL. Their results showed no significant difference in mean fasting glucose and mean fasting insulin levels. There was no significant insulin resistance in the study group. since the difference in HOMA-IR index between the study and control groups was not statistically significant, it implies that spontaneous pregnancy loss was not associated with insulin resistance in our study population. The incidence of insulin resistance in our study population was $8 \%$ in women with previous one abortion, whereas the incidence in recurrent abortions was $17.6 \%$. This is in correlation to the findings of the study by Craig LB et al 10 .

The gold standard for assessing insulin resistance is the Hyperinsulinemic- Euglycemic clamp technique. This technique is rather elaborate, time-consuming and not feasible in all centers. The HOMA method has been reported to correlate well with the clamp technique and thus provides a good assessment of insulin resistance.

In our study it was found that majority of abortions with thyroid abnormalities and insulin resistance in the abortus group were missed abortions, $66.6 \%$ with TFT abnormalities and $100 \%$ with insulin resistance. the association between insulin resistance and missed abortions was found to be statistically significant ( $\mathrm{P}$ value $<0.05$ ). when the results of our study was analysed, only 2 patients with thyroid abnormality had insulin resistance. The association was not statistically significant. The results were similar to the study by Agarwal et al 11. The final result of our study shows that in our population of women with spontaneous abortions, $27.9 \%$ had endocrine abnormalities namely thyroid disfunctions and insulin resistance.

\section{CONCLUSION:}

Thyroid function abnormalities play a role in the etiology of spontaneous abortions and recurrent abortions. Based on our results, spontaneous abortions seem to be commonly associated with subclinical Hypothyroidism. Therefore, serum TSH levels should be measured as a routine screening test in pregnancies even with history of one spontaneous abortion.

Higher levels of fasting blood glucose, fasting insulin levels and higher percentage of insulin resistance were reported in patients with spontaneous abortions, although the differences were not statistically significant. Insulin resistance has not been identified as a significant factor in our patients with recurrent pregnancy loss, though it was significantly high in women with missed abortions. because our sample size was small, we cannot categorically conclude that there is no correlation between insulin resistance and spontaneous abortions.

\section{REFERENCES:}

[1]. Backos M, Regan L. (2007), “ Recurrent Miscarriage. In: James DK, Steer PJ, Weiner CP, Gonik B, Editors". High Risk Pregnancy, 3 rd edition. ELSEVIER, 105-25.

[2]. Regan L. (1991), "Recurrent Miscarriage". British Medical Journal; 302: 543-44

[3]. Ford HB, Schust JD. (2009), "Recurrent pregnancy loss: Etiology, diagnosis and therapy". Reviews in Obstetrics and Gynecology; 2: 76-83.

[4]. Manuel J, Garzon C. (2004), "Easy and quick assessment of Insulin sensitivity". J Clin Endocrinol Metab; 89: 1481-4.

[5]. Donmez M, Sisli T, Atis A, Aydin Y. (2005), "Spontaneous Abortions and Thyroid Functions". Perinatal Journal; 13:110-4.

[6]. Matsua K, Kabarlein G, Burrow G. (2000), "Spontaneous pregnancy termination and thyroid abnormalities". Hum Reprod; 15: 163-79.

[7]. Pratt D, Novotny M, Kaberlein G. (1993), "Anti thyroid antibodies and the association with non-organ specific antibodies in recurrent pregnancy loss". Am J Obstet Gynecol; 168: $837-41$

[8]. Glinoer D, Soto MF, Bourdoux P, Legune B, Delange F, Lemone M, Kinthaert J,Robin C, Grun J, De Nayer P.(1990). " Pregnancy in patients with mild thyroid abnormalities : Maternal and Neonatal Repercussions. J Clin Endocrinol Metab; 73:421-7.

[9]. Diejomoah M, Jirous J, Al-Azemi M, Gupta M, Al-Jaber M, Farhat R, Mohd A. (2007), “ Insulin resistance in women with recurrent pregnancy loss of unknown etiology". Med Princ Pract; $16: 114-8$

[10]. Craig LB, Ke RW, Kutteh WH. (2002)." Increased prevalence of insulin resistance in women with history of recurrent pregnancy loss". Fertil Steril; 78: 487-90.

[11]. Agarwal MM, Dhatt GS, Punnose J, Bishwai B, Zayed R. (2006). " Thyroid function abnormalities and anti-thyroid antibody prevalence in pregnant women at high risk for gestational diabetes mellitus". Gynecol Endocrinol; $22: 261-6$. 